\title{
Social inclusion through ageing-in-place with care?
}

\author{
PATRICK BARRETT*, BEATRICE HALE $\dagger$ and ROBIN GAULD $\dagger$
}

\begin{abstract}
The onset of ill-health and frailty in later life, within the context of the policy of ageing-in-place, is increasingly being responded to through the provision of home care. In the philosophy of ageing-in-place, the home provides for continuity of living environment, maintenance of independence in the community and social inclusion. The provision of assistance to remain at home assumes continuity in the living environment and independence in the organisation of daily life and social contact. This paper explores the changes that occur as a result of becoming a care recipient within the home and concludes that the transition into receiving care is characterised by discontinuity and upheaval which tends to reinforce social exclusion. We draw on the rites of passage framework, which highlights social processes of separation, liminality and reconnection, in analysing this transition to enhance understanding of the experience and gain insights to improve the policy and practice of home care. Separation from independent living leads to a state of liminality. The final stage in the rites of passage framework draws attention to reconnections, but reconnection is not inevitable. Reconnection is, however, an appropriate goal for the care sector when supporting frail or disabled older people through the transition into becoming a home-care recipient.
\end{abstract}

KEY WORDS - ageing-in-place, formal care, liminality, social inclusion, reconnective care work.

\section{Introduction}

In this paper, we explore the concept of social inclusion alongside that of ageing-in-place with care. Doing so raises the questions: what do we mean by social inclusion for people in this particular population and can social inclusion be achieved, maintained or improved through the provision of care at home? The widely accepted policy of ageing-in-place, which we define

* Public Policy Programme, School of Social Sciences, The University of Waikato, New Zealand.

$\dagger$ Department of Preventive and Social Medicine, The University of Otago, New Zealand.

\section{CAMBridge}


in this paper as support to remain in a long-term family home (see Davey et al. 2004; Means 2007), is leading to an increasing number of frail or disabled older people receiving formal home care. By formal home care, we mean services provided by public, private or community and voluntary organisations which support older individuals in domestic and personal care tasks. Many countries have responded to increasing numbers of frail older people by increasing the level of formal home-care provision (Organisation for Economic Co-operation and Development (OECD) 2005; Timonen 2005: 47 ). Within the philosophy of ageing-in-place with formal care, home as a place of care is intended to provide continuity of environment, the maintenance of independence in the community and, therefore, social continuity and social inclusion. Home, across all cultures, is a taken-forgranted concept, generally characterised by warmth and stability, safety, familiarity and autonomy. The assumption is that home is the place where the provision of support and care will best ensure wellbeing, comfort and safety, and that cared-for individuals will retain power to control and direct their lives. Through the provision of assistance to carry out the essential activities of daily living, the individual is assumed to be able to maintain continuity in the living environment, in the organisation of daily life and in social networks.

In this paper we focus on this time of life and explore the character of the changes that occur as a result of increasing dependency within the home. We draw primarily on research into the experience of dependence on care within the community by Barrett et al. (2005) and Hale (2006). The Barrett et al. (2005) study involved interviews with 41 community-dwelling older people in Tauranga, New Zealand. The research examined the processes involved in becoming frail, the impact of various trigger events, and the role of formal and informal support networks in mediating the transition into frailty. The Hale (2006) study examined the day-to-day experiences of 15 older people living in Dunedin, New Zealand, who were receiving formal and informal (primarily family) care, the care-giving experiences of 12 family carers, and the experiences of nine formal home-care workers. Both studies suggested that making the transition into receiving care in the home is not unproblematic. We draw on the rites of passage framework in the analysis of this transition to enhance understanding of the experience and gain insights to improve the policy and practice of home care. The rites of passage framework, proposed by the anthropologist Van Gennep (1909/ 1960) to understand social rituals which mark transitions between different life stages, highlights processes of separation, liminality and reconnection. Each stage in the framework is worthy of close consideration, but in this paper we focus mostly on the second stage of liminality, and on the potential of highquality care services to assist older people to move from liminality into the

\section{CAMBridge}

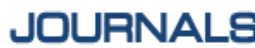


third stage of reconnection. Reconnection, however, is not inevitable, but does imply that social inclusion is an appropriate goal for the care sector when supporting frail or disabled older people through the transition into becoming a home-care recipient.

\section{The transition into ageing-in-place with care}

Life transitions continue in old age, for example, from marriage to widowhood, or from home to sheltered care and/or residential care (Frank 2002; Hyde and Higgs 2004; Percival 1997; Shield 1988, 1997). Such transitions can be defined as critical phases during which significant developmental, social or economic change takes place. Our approach to studying the transition into becoming a home-care recipient employs Van Gennep's (1909/1960) tripartite rites of passage model which depicts three distinct processes: (a) separation from the current stage through some type of disjunctive experience involving the removal of the individual from his or her former status; (b) a stage of liminality, an 'in-between' stage characterised by an unsettled social status and identity and a suspension of normal social contact; and (c) a readmission, reconnection or reintegration into society in a newly acquired status. Van Gennep also observed that the social context of such rituals determined the responses of the wider society towards the ritual participant and their acquisition of a new social status. The rites of passage model is widely employed to explain life-stage transitions and appears to have ready applicability to understanding change in old age. For example, Janlov, Hallberg and Petersson (2006: 334) observed a number of distinct phases in late life transitions: 'a starting point of change, through a period of instability, discontinuity, confusion and distress to a new beginning or period of stability'.

Focusing on these phases - separation, liminality and reconnectionprovides a structure to examine the complex changes in what is, by comparison with the types of rituals Van Gennep observed, the uncelebrated transition into receiving care at home. The choice to use the rites of passage framework as an overarching analytical tool developed from our reading and categorising of data in New Zealand studies (Barrett et al. 2005; Hale 2006) and also from the social gerontological work of Hazan (1984), Moore and Myerhoff (1977), Shield (1988, 1997) in terms of residential care, Hallmann (1999), Hugman (1999), Teather (1999), in family care-giving, Hockey and James (1993, 2003) in considering passages through the lifecourse, Frank (2002) observing an incomplete rite of passage in her study of assisted living, and Parks (2003) with her focus on care at home. 
Understandably, to date, the main focus in the study of transitions among older people in care has been on the movement from one site of care to another, from home to hospital (Hirst 2002, 2004), to residential care (Shield 1997), between facilities, within residential care (Diamond 1992) and into assisted living (Frank 2002). There has been less attention, however, on the transitional experiences of older people who experience the onset of frailty or disability but, with additional care services, are able to remain in their own home. The emphasis in many OECD countries on ageing-in-place (Means 2007: 68-9; OECD 2005) points to the likelihood of growth in the number of older people living at home with support, and suggests this life-stage transition will become increasingly common and therefore worthy of closer examination. It is, as we have identified (Hale, Barrett and Gauld 2010), a transition into supported independence in the home, involving a change from home as a place of independent living to home as a place of care, with altered social statuses and relationships, and in Hockey and James' (2003: 25) words, 'new rules, roles and obligations'. There are changes for both the person needing care and for other household members, as implied in the following passage by Efraimsson, Hoglund and Sandman:

... natural caring was changed into patient-care-giver relations and the home became a public room. The patients had to deal with decreased abilities and the family members with adjusting to caring need. (2001: 813)

To obtain a better understanding of this transition, we focus on those factors that define the home as a place of independent living - its spatial features ( $c f$. Lawton 1983), issues of temporality (Twigg 2000), and social relationships and networks (Barrett et al. 2005; Efraimsson, Hoglund and Sandman 2001; Gubrium and Sankar 1990; Hale 20o6; Janlov, Hallberg and Petersson 2006; Twigg 2000). Hugman captures the interlinked nature of these factors in the observation that:

Home is the location in which, through the use of time and space, self-hood is enacted in the routines and decisions of daily living. (1999: 201)

We thus focus on the changes in spatial, temporal and relational terms with a view to understanding better the experience of becoming a home-care recipient. Using the rites of passage model imposes a structure on the changes, and although this framework is not the only means of understanding such changes, it has the ability to highlight certain features of change, and therefore brings to the surface characteristics that might otherwise be taken for granted. This framework also implies recognition of the risk of failing to complete the passage and the potential for the older person to remain in a state of liminality, which can be conceived as disconnection from self and

\section{CAMBRIDGE}


from society. We therefore examine the changes in terms of the tripartite structure, beginning with the first stage, of separation.

\section{Separation from independent living}

From our observation (Barrett et al. 2005; Hale 2006), being assessed to determine functional capacity, level of need and eligibility for assistance is the critical social interaction that initiates the rite of passage. Although assessments typically take only an hour or two, they create a potentially prolonged stage of uncertainty and anxiety related to the question of remaining in one's own home and to questions of care services to be provided. Separation is typically initiated by symptoms and behaviours that bring the older person to the attention of family members and health professionals (Kaufman 1994). Poor health, the loss of physical abilities, energy or social relationships are common triggers initiating the transition.

These symptoms or behaviours prompt the involvement of health and allied care professionals and/or family members. Assessments are often systematically implemented following discharge from hospital, or on the referral by the family doctor, or community-based groups (e.g. arthritis, asthma, cardiovascular health problem support groups). The changing interactions with family members, and new interactions with health professionals and home-care assessors constitute the social exchanges that signal the rite of separation. The assessment is performed by needs assessors, case managers, nurses, social workers and care co-ordinators, professionals who are likely to be strangers to the older person, and who are the gatekeepers of help. The procedure is carried out by means of face-to-face interviews, usually in the individual's home, which cover physical and cognitive abilities as well as the family and social situation. Standardised assessment schedules aim to account for: a person's background and living situation, the nature of current formal and informal support networks, income sources, medical history and diagnoses, current treatments, communication ability, vision and hearing, mobility, personal care ability, capacity for safe household management, and cognitive functioning. It seems simple enough, but in the assessment the older person's life is laid bare. The process is understood by the older person as a type of test:

It felt like an exam.

[I was] worried in case I didn't qualify. (Hale 2006: 96)

The older person enters these social exchanges from a lesser position, one of little power. The power to determine eligibility in these exchanges lies with the assessors and is framed by the institutional roles, professional identities and broader social structures that constitute them. In the exchanges there is

\section{CAMBRIDGE}


potential for the will of the older person to be overridden - his or her voice silenced, and his or her preferences ignored (Janlov, Hallberg and Petersson 2006: 27). This is evident through the way the dialogue about the older person's situation is controlled by the assessor. It is the assessor who introduces and closes off the topics that are examined. The overt exercise of power is evident in practices such as those described in Hale's (2006: 96) study where a young occupational therapist asked an older woman to undress and dress again, to prove whether and how she could dress herself. The older woman commented:

Why couldn't she take my word for it? Why did I have to go through all that as well? I needed help - couldn't they just see that?

The assessment contains many elements found in ritual practice: a clear sense of purpose; repeated activities in a set pattern; and the subordination of personal experience to pre-established practices. In the analysis of rituals, the 'separation' implied in the first step of the rite of passage is understood as involving the stripping of social status. We suggest a similar, though unintended, experience occurs for older people facing the assessment process in which their lives are laid bare and where, as Turner (1969: 93) claims, in a rite of transition they become 'invisible' as the people they used to be.

\section{From separation to liminality}

The post-assessment stage corresponds to a liminal phase, experiences of disorientation in the face of changing social, spatial and temporal environments, leading to what can be defined as improvisatory practices. The experience involves conflicting emotions, an uncertain identity and a strong sense of dis-connectedness. The older person moves to a state of uncertainty and confusion, and an unsettled social status: 'am I someone with a disability, am I entitled to help?' This confusion is typical of Van Gennep's second stage, liminality (derived from the Latin 'limen' or threshold), which involves the suspension of 'normal' social contact and an unsettled social status and role. We develop this theme further through a brief exploration of the spatial, temporal and relational experiences of older people following their assessment. From this summary, we move to consider the experiences that constitute the third stage, or reconnections, which we suggest points to strategies to enhance social inclusion.

\section{The experience of liminality: spatial dimensions}

The onset of frailty or disability such that care is needed to remain at home leads to disruptions in the spatial environment of the older person.

\section{CAMBridge}


To maintain an increasingly disabled body at home requires conscious spatial decisions. Laws' (1997: 25) comment that residential care represents 'new landscapes ... created to house ageing bodies' also relates to home care. Common instances of the reordering of space in this context involve things like the re-modelling of the kitchen to allow the reaching of items; reorganising of the downstairs part of the house into a bedroom/living area; closing off spare rooms or rooms not accessible or in use; parts of the house becoming chilly, musty and out of bounds; and the recreation of spaces, such as the kitchen, to compensate for loss of mobility and function, and provide for multiple activities such as sitting, entertaining, cooking and eating (Swenson 1998; Wiles 2005). Such adaptation helps maintain control and independence, but it also makes the disability clearly visible, a defining feature of the space, a constant reminder. Home arrangements express identity, and such modifications represent the changing identity (Rowles and Chaudhury 2005). House modifications and the introduction of visible assistive devices are material indicators of the change the older person experiences. As individuals are moment by moment confronted with physical reminders of their need for assistance, former meanings and identities associated with home are threatened or compromised.

\section{The experience of liminality: temporal dimensions}

Liminal experiences also involve temporal disruptions. At one level, this is simply the disruption in the ability to maintain control over the organisation of one's daily routines. There are, however, a number of dimensions here, one of which is the loss of the capacity to maintain a personal daily rhythm. Autonomy in this dimension refers to the power over personal organisation and the maintenance of an acceptable temporal rhythm to the day, the week, or the month (Haggblom-Kronlof et al. 2007; Larsson, Haglund and Hagberg 2009). Daily rhythm is part of what has been laid down during the lifecourse, and thus part of an individual's routine expectations. Such daily rhythms structure the organisation of the self and the home, and provide markers for the experience of the day: for example, morning is for tasks, after lunch is either siesta or leisure time, then another meal, depending on the culture. Maintaining our own daily rhythm is part of continuity and selfdetermination, part of keeping life on track, but such patterns are interrupted by the onset of frailty and disability.

Late life ageing itself slows people down, and with frailty and disabilities, the steady pattern of everyday activities is interrupted. Taken-for-granted simple tasks need to be broken down into their constituent parts, through the inability to perform them readily, revealing temporalities that were previously hidden in an embodied memory, once performed effortlessly

\section{CAMbridge}


through practice, but now requiring concentrated attention. Further, as older people interact with service agencies they must reconcile their own slower 'disability time frames' with those of services (Twigg 2000). When care is provided, it is typically organised according to the time conventions of the ordinary working day and, in the New Zealand context where directive control does not lie with the older person, its delivery is managed by an external agency. The tensions between the 'clock' time of the funders, agencies and workers, and the personal time of the frail older person reinforces liminal experiences and compromises the autonomy of the older person. Despite the negotiation processes that are recommended, these being intended to address the power imbalance (Olaison and Cedersund 2006), the various multiplicities of time which accompany the advent of formal home care are a significant disruption.

\section{The experience of liminality: relational dimensions}

For many such older people the disruptions caused by the onset of frailty or disability leave them with significant social challenges (Janlov, Hallberg and Petersson 2006; Twigg 2000). The processes contributing to this are familiar. A combination of: physical mobility and transport problems; unstable and fluctuating health; feelings of not being able to keep up with the pace of other people; an unwillingness to inconvenience others; loss of confidence and fear of accidents or falls; an unwillingness to venture out at night; and shrinking social circles, all influence the ability to sustain communityfocused networks. With policies of ageing-in-place, more formal care is required, partly because family members are today unable to provide the level of care to meet the increasing severity of need. New relationships are formed with needs assessors, care agencies and care workers. Relationships with a spouse or an adult child must also adapt to deal with the changed roles brought on by disability and increased dependency. Further, interactions with family members as well as relationships with agency co-ordinators and in particular care workers are underpinned by normative views, often ageist stereotypes. Often these relationships, which tend to involve the 'management' (Aronson 1999) of the older person, are conducted in such a way so as to reinforce passivity and dependency, and undermine autonomy and agency (Olaison and Cedersund 2006; Szebehely 1995).

\section{Liminality and social exclusion}

Each of these dimensions, covered only briefly here, illustrates an aspect of discontinuity that is part of the experience of becoming a recipient of

\section{CAMBRIdGe}


home care. Liminality, as we have operationalised it, implies that an individual experiences a type of disconnection from the social world as he or she passes through this life-stage transition. Remaining at home with care does not automatically lead to the autonomy, independence and social inclusion implicit in the motivation behind the policy of ageing-in-place. In fact, as the review above shows, for many older people remaining at home with care can intensify experiences of liminality - disconnectedness from self, from family, from the home, and from the broader community. The result is experiences that are similar to Room's (1995: 243) definition of social exclusion: 'inadequate social participation, lack of social integration and lack of power'.

Social exclusion is also taken to apply to exclusion from material resources, exclusion from civic life, exclusion within neighbourhoods and exclusion from basic services (Scharf et al. 2002). Ageing-in-place with chronic ill-health was an important category of older people who were found to be socially excluded by Scharf, Phillipson and Smith (2005). This constituted social disconnectedness and the loss of 'voice' - a loss of power to influence the course of one's life - this voicelessness reinforcing detachment from wider communities. As it is, social relationships at this stage of life tend to become more restricted and circumscribed, and many older people report being very lonely (Hague and Kirkevold 2010; Victor et al. 2002). For those dependent on care at home, social exclusion thus includes spatial exclusion, confinement behind closed doors in the hidden geographies of homes, making it difficult to engage outside the home and reinforcing social isolation. The notion of temporal liminality also captures the loss of power to influence the organisation of daily life.

Is liminality, then, the same as social exclusion? Clearly there are differences in the origins of the concepts. Liminality in the rites of passage framework is understood as a temporary phase in the life-stage transition process. It does refer to, as noted, social disconnectedness, social invisibility and an uncertain social identity. Given its portrayal as a transitionary phase that is followed by social 'reconnection', it does draw attention to processes in achieving the converse state of social inclusion. That is, conceptualising living at home in old age with formal care as a new life stage, the reaching of which involves passage through stages of separation and liminality, draws attention to what is required to complete the passage and achieve a state of reconnection. Drawing on Hale's (2006) long experience in the care sector and her research into the experience of care-giving and care-receiving, we now give attention to outlining how home care has much potential to support reconnection in these contexts.

Home-care workers are a critical resource for supporting independence and for achieving social inclusion. However, a limited view of what home care is, with care being taken merely to be the completion of practical tasks, is 
unlikely to facilitate these goals. A simple task-focused approach to care work that focuses on ensuring the house is hygienic and the person clean and comfortable, as Jenny Morris (1993) pointed out, can reinforce the conditions typically associated with negative views of residential care, except in the more isolated environment of the home. Taking care of domestic chores and assisting with personal care will not on its own provide care recipients with the wherewithal to make the transition from experiences of disconnection and liminality. What, then, characterises reconnective homecare work?

\section{Reconnective home care}

Reconnective care practice demands more than merely basic knowledge about the performance of domestic work tasks and simple personal care skills. Carrying out the complex duties of care and managing the relational aspects of this work requires a specialised knowledge and skills. Reconnective practice is characterised by the promotion of 'directional autonomy'supporting older people to select the services required and to set the course of their lives. This involves adopting consultative and inclusive ways of working, leading to processes of negotiation that enable the care worker to give power back to the older person and reinvigorate their engagement in managing the organisation of their home and personal life. The care task in this way of working extends beyond ministering to the clinical and functional limitations of the cared-for person to include actively giving them greater autonomy. Flexibility, then, is also a key principle that should underpin practice models and this extends to flexibility with budgets and task selection to allow for greater client involvement in goal setting and the development of care plans.

There needs to be a strong rehabilitative focus in supporting client direction. In many respects the care worker should work to rehabilitate the power of the older person within the domain of their own home. As it is, one of the signs of effective care-work relationships is that the cared-for person often feels as if he or she can ask for additional tasks outside of those they are assessed as being eligible to receive. Support should be given to supporting the choices made by older people themselves, beyond domestic and personal care, and in the area of social and recreational activities. Social participation is critical for wellbeing and the care and support tasks should extend to cover this.

Reconnective practice recognises the value of the relational aspect of care ( $c f$. Nolan et al. 2004). While the official language of home-care work concentrates on the performance of specific tasks in a timely fashion, it is the

\section{CAMBRIDGE}


qualitative, emotional connections in caring for another person, the listening and talking that are a part of it, that allows, as Stone (2005: 283) suggested, those receiving care to 'express who they are and to preserve their identities as something other than sick, declining persons'. Hale (2006: 168) found that receivers of care were less concerned with the performance of the practical, physical care tasks than with the personal connection implicit in the care relationship, and this was captured in the comment by one care recipient who said: 'Will they really care about me or will they just be there for the work'. Reconnective care work, then, is characterised by an engaging and positive inter-personal environment. This has long been known - Eustis and Fischer (1991) commented that 'excellent care in terms of good practical skills is less appreciated by recipients than poorer physical care from more compatible workers'. It is the conversations which envelop the practical, physical tasks of caring that allow for the establishment of intimacy and for home-care workers 'to give clients their lives back and to make a difference - which is far more important to them than, say, giving a bath or a meal' (Eustis and Fischer 1991). This is why the cared-for person often tracks the care-giver through the house while domestic and other tasks are performed.

The relational aspect of care work sits uncomfortably alongside managerial or bureaucratic demands for accountability, impartiality, predictability and efficiency (Twigg 2000: 162). The need for agency control means the locus of authority in the care relationship lies outside the home, with the agency, care service co-ordinators and needs assessors. The home-care relationship is threatened by the bureaucratic or organisational controls which influence how the worker carries out tasks, and care recipients for the most part have to live with the rules of the agencies, and the policies which govern these rules.

Because those who pay for care fear the cost of unrestrained caring or compassion, they seek to contain that care and compassion by mechanisms that include limits on reimbursement. The result is the managerial requirement that care be counted, monitored and carefully circumscribed. It leads to its transformation into something society can underwrite, something precisely defined, unambiguous and limited-a type of contract. This requires taking what are the unseen, fluid and dynamic qualities of relationships and reducing them to basic elements that are observable and countable. Doing so shapes the nature of the care-giver contact with the people they care for. It means constraining the relationship between the care-giver and the cared-for person in terms that are acceptable between the care-giver and the agency. This results in care-givers being less able to respond flexibly to changing needs and requests, or even entering into dialogue with the cared-for person about what tasks are wanted. We suggest 
that these policies and bureaucratic arrangements which frame particular service settings have a tendency to undermine the likelihood of reconnective practice.

The contract in the form of the home-care plan lists tasks the care worker is required to carry out, and typically none of these plans include talking to or listening to the older person. But caring relationships usually imply being responsive to the situation and expressions of need, to perceived needs at the time. Hale (2006) found that one of the characteristics of an effective care relationship, once established, was the receivers of care felt they could ask for additional tasks to be done, outside of those provided for in the assessment process: letters to be posted, washing to be hung out, dustbins put out or taken in, or even extra cleaning or preparation of food. But where there is a rigidly enforced care contract, care-givers say, 'I'd like to do that for you but can't, given the terms of the care plan'. The point, as Stone says, is:

[w] hen care is paid for by third parties, instead of by care recipients themselves, the recipients also cede power to the payers. They lose power to shape and define the care they receive. In all the goal setting and rule-making by payers, recipients' goals count for little. (2005: 286)

Our own point here is that home care is delivered within the context of contradictory language which, on the one hand, frames the work within the formal limiting language of contracts and, on the other, within the intimate language of relationships. This duality between the intimacy of care and home and the language of paid work, accountability and contracts (Ungerson 2005) captures an important tension in seeking to promote reconnective ways of home-care work.

Task-focused and rigidly time-managed approaches work against the adoption of rehabilitative strategies that support the autonomy of the care recipient. Care recipients want reliability and flexibility (Francis and Netten 2004) and care workers want autonomy so they can manage with flexibility the requirements of the client. The result is the stifling of opportunity for the 'getting alongside', relationship-focused practices that reinforce the independence and autonomy of the cared-for person, and instead the reinforcing of compliance, obedience and passivity.

This has led to widespread dissatisfaction with this way of working, among both care-givers and the receivers of care. Care recipients commonly criticise the lack of opportunity for flexibility and control over the tasks performed and care workers report insufficient time to complete specified tasks. The fact is that agency-specified tasks are often exceeded, normally in breach of agency contracts and the job descriptions of care-givers, but this is not recognised and compensated given that the work is carried out in the invisibility of the home. The fiction of a production-line approach to care,

\section{CAMbridge}

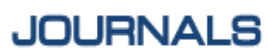


where workers perform as many task-focused hours of work as possible, where there is impartiality and predictability in service provision - that everyone will receive that to which they are entitled - continues to inform the policy approaches to care delivery.

There is also the argument that such constraints lead to the prevention of abuse of the care receiver. Parks' (2003) conclusions, based on her personal experience as well as research observations, recognise the benefits of the relational side of care-giving, as well as the potential for over-involvement and abuse. Close emotional engagement, she suggests, does provide potential to manipulate and withhold warmth. Warm relationships are those with a mutual flow of support and which are ideal. They can be contrasted, according to Ungerson's (2005) typology of home-care relationships, with 'cold', 'cool' and 'hot' relationships. Cold relationships are those that are angry, resentful and of limited duration; cool relationships are professional with a detached focus by the care worker only on the work; and hot relationships are those where relationships are volatile but long-standing and often involve co-residence of family or worker.

The fear of abuse through over-involvement is a fear that workers will use their greater power to maintain control over their work and the cared-for person. Lachs and Pillemer discuss the potential and actual abuse of care recipients by both formal and informal home care-givers, noting that 'a shared living arrangement is a major risk factor for elder abuse' (2004: 1265 ). The potential for abuse in poorly resourced and supported care-work environments is real.

\section{Facilitating reconnective practice?}

It is high time that policy makers, planners and professionals began a proper dialogue with older people concerning their needs and wants ... It is no longer sufficient to go on adopting a 'we know best' attitude. (Bernard 1991: 12)

Bernard's comments signal a debate which has had little airing in the public domain concerning the question of whether we see ageing at home with care as a means of supporting independence, or whether we see it in terms of a service focused simply on meeting physical needs. We suggest reconnective care work supports the former, and that it requires greater importance to be given to the relational dimensions of care-work practice, greater emphasis given to promoting directional autonomy, and the flexibility within care programmes and contracts to achieve these ways of working. A significant policy challenge is to develop formal systems of care that provide for such flexibility. A sufficient allocation of time to carry out care work tasks and the allocation of greater levels of directional control to care recipients should be 
key policy objectives. In the New Zealand context, there are a few community services which take this line. Two of these are: Enliven, a home-based, restorative support initiative which develops programmes on a client by client basis, and Individualised Funding, a programme which entitles individuals who are assessed by the Needs Assessment and Service Coordination Agency as eligible for disability support and services. These are small-scale services which follow a philosophy of recipient autonomy.

There is a need also to strengthen the capacity of care workers. In the New Zealand context it is generally accepted that there is a need to provide better training for home-care workers, along with improved work conditions, professional support and rates of pay (Health Workforce Advisory Committee 2006). This is especially important given the increasing severity and complexity of client needs requiring greater skills of home-care workers. As it is, there are widespread concerns about the low level of training of workers in this sector, especially when they are increasingly being asked to carry out tasks beyond their scope of practice and training. They work, largely, in isolation and there is limited opportunity for monitoring and supervision. Support in terms of monitoring and 'supervision' in the social work sense will involve providing opportunities to reflect on care-work practices, and discussing issues and problems and how best to deal with them. Colleagueship, the opportunity to discuss cases, the opportunity to work in a team, and improving the support given by agencies to care workers have all been identified as factors that will contribute to improving the quality of home care (Burns et al. 1999; Stone 2005; Willner 2000). And as we have noted (Hale, Barrett and Gauld 2010, Chap. 2), many countries will face a significant challenge in simply meeting the growing demand for home-care workers (Hugo 2007; New Zealand Department of Labour 2009; OECD 2009).

A community development approach emphasising the inclusion of older people in the carrying out of research (as in Barrett et al. 2005), and in planning and advocacy, has much potential to contribute to change in the broader community environment. Research, advocacy and lobbying by organisations which work with this particular group of older people need to continue. Further, since older people are the experts for their own situations, a community development approach will seek to include them as colleague researchers. Barrett et al. (2005) did draw on older volunteers in their analysis of the experience of the transition into frailty in later life. This was mirrored in the approach of the Older People Researching Social Issues (OPRSI) project which provided for the mining of their own experience:

Older people want real or purposeful involvement ... they want to know that the time and energy they put into the research is recognised, that their views are taken seriously, and that they will be informed about the outcome of the research. 
Many older people will benefit from the support of universities and, if training for research, involvement in ongoing research. (Clough 2007)

The transformative potential of a positive care relationship is linked with the qualitative, emotional connections that are a part of caring - the personal connections that are established. Such relationships provide hope in the face of loneliness and isolation, and can support the passage into new, accepted identities. Our review suggests that the fact that such care is provided on a formal basis, for pay, does not necessarily undermine its restorative potential. Formal home care can address both the physical and the emotional needs of the cared-for person. It is agency control and the limiting language of contracts that are a significant threat to the potential for reconnective practice. Task-focused and rigidly time-managed forms of care undermine the potential for flexibility and responsiveness that is the essence of a caring relationship, and therefore the potential of the care worker to support the transition into the new stage of supported independence.

\section{Conclusion}

Ageing-in-place is accepted as the preferable approach to housing an older and frailer population, but it is not yet clear that this is matched by an appreciation of the crucial role played by home-care work in achieving the underpinning purpose of social inclusion. Caring is a complex phenomenon and it tends to be the concrete, observable tasks that are used to define and describe it. But care is more than the mere performance of domestic and body-work tasks. It is the relational aspects of care that facilitate passage from experiences of liminality and disconnection to a stage of supported independence. Our argument is that the recipient of care is not being well served by systems that do not address the disconnection they experience in their lives brought on by the development of disability and frailty. The homecare sector is still in its development stage. There is considerable potential for it to be shaped in more positive ways that will promote the type of practice we have suggested. The goal is better outcomes for older people. The challenge is to promote the development of governance arrangements and models of practice that enhance the interactions between older people who receive home care and those who care for them. Workers need to be valued through support, supervision and improved pay. Home care can merely assign people to an existence at the margins, or it can offer the opportunity for reconnection. Care workers have the potential to play a critical role in achieving the latter, providing social inclusion is recognised as a significant goal.

\section{CAMBridge}

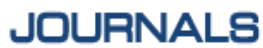




\section{References}

Aronson, J. 1999. Conflicting images of older people receiving care: challenges for reflexive practice and research. In Neysmith, S. M. (ed.), Critical Issues for Future Social Work Practice with Aging Persons. Columbia University Press, New York, 47-70.

Barrett, P., with Kletchko, S., Twitchin, S., Ryan, F. and Fowler, V. 2005. Transitions in Later Life: A Qualitative Inquiry into the Experience of Resilience and Frailty. University of Waikato at Tauranga, Tauranga, New Zealand.

Bernard, M. 1991. Vision for the future. Nursing the Elderly, January/February, 10-12.

Burns, J., Dwyer, M., Lambie, H. and Lynch, J. 1999. Homecare Workers: A Case Study of a Female Occupation. Ministry of Women's Affairs, Wellington.

Clough, R. 2007. Older People Research Social Issues (OPRSI), ARVAC. Available online at www.arvac.org.uk/docs/info_bull95e.html [Accessed 1 May 20og].

Davey, J., Nana, G., de Joux, V. and Arcus, M. 2004. Accommodation Options for Older People in Aotearoa/New Zealand. Centre for Housing Policy Aotearoa, Wellington.

Diamond, T. 1992. Making Gray Gold: Narratives of Nursing Home Care. University of Chicago Press, Chicago.

Efraimsson, E., Hoglund, I. and Sandman, P. 2001. The everlasting trial of strength and patience: transitions in home care nursing as narrated by patients and family members. Journal of Clinical Nursing, 10, 813-9.

Eustis, N. N. and Fischer, L. R. 1991. Relationships between home care clients and their workers: implications for the quality of care. The Gerontologist, $\mathbf{3 1}, 4,447^{-} 5^{6}$.

Francis, J. and Netten, A. 2004. Raising the quality of home care: a study of service users' views. Social Policy and Administration, 38, 3, 290-305.

Frank, J. B. 2002. The Paradox of Aging in Place in Assisted Living. Bergin and Garvey, Westport, Connecticut.

Gubrium, J. and Sankar, A. 1990. The Home Care Experience. Sage, Newbury Park, California.

Haggblom-Kronlof, G., Hultberg, J., Eriksson, B. and Sonn, U. 2007. Experiences of daily occupations at 99 years of age. Scandinavian Journal of Occupational Therapy, 14, 3, 192-200.

Hague, S. and Kirkevold, M. 2010. Older Norwegians' understanding of loneliness. International Journal of Qualitative Studies on Health and Well-being, 5, 4654. Available online at www.ijqhw.net/index.php/qhw/article/view/4654/5381 [Accessed 13 March 2011].

Hale, B. 2006. The meaning of home as it becomes a place for care: a study in the dynamics of home care for older people. Unpublished PhD thesis, University of Otago, Dunedin, New Zealand.

Hale, B., Barrett, P. and Gauld, R. 2010. The Age of Supported Independence: Voices of Home Care. Springer, Dordrecht.

Hallman, B. 1999. The transition into eldercare-an uncelebrated passage. In Teather, E. K. (ed.), Embodied Geographies: Space, Bodies and Rites of Passage. Routledge, London, 208-23.

Hazan, H. 1984. Continuity and transformation among the aged: a study in the anthropology of time. Current Anthropology, 25, 5, 567-78.

Health Workforce Advisory Committee 2006. Care and Support in the Community Setting. Ministry of Health, Wellington.

Hirst, M. 2002. Transitions to informal care in Great Britain during the 1990s. Journal of Epidemiological Community Health, 56, 8, 579-87.

Hirst, M. 2004. Health Inequalities and Informal Care. End of Project Report. Social Policy Research Unit, University of York, York, UK. 
Hockey, J. and James, A. 1993. Growing Up and Growing Old. Sage, London.

Hockey, J. and James, A. 2003. Social Identities Across the Life Course. Palgrave Macmillan, Basingstoke, UK.

Hugman, R. 1999. Embodying old age. In Teather, E. K. (ed.), Embodied Geographies: Space, Bodies and Rites of Passage. Routledge, London, 193-207.

Hugo, G. 2007. Contextualising the 'crisis in aged care' in Australia: a demographic perspective. Australian Journal of Social Issues, 42, 2, 169-82.

Hyde, M. and Higgs, P. 2004. The shifting sands of time: results from the English Longitudinal Study of Ageing on multiple transitions in later life. Ageing International, 29, 4, 317-32.

Janlov, A., Hallberg, I. and Petersson, K. 2006. Older persons' experience of being assessed for and receiving public home help: do they have any influence over it? Health and Social Care in the Community, 14, 1, 26-36.

Kaufman, S. 1984. The social construction of frailty: an anthropological perspective. Journal of Aging Studies, 8, 1, 45-58.

Lachs, M. and Pillemer, K. 2004. Elder abuse. The Lancet, 364, 9441, $1263-72$.

Larsson, A., Haglund, L. and Hagberg, J. 2009. Doing everyday life-experiences of the oldest old. Scandinavian Journal of Occupational Therapy, 16, 2, 99-109.

Laws, G. 1997. Spatiality and age relations. In Jamieson, A., Harper, S. and Victor, C. (eds), Critical Approaches to Ageing and Later Life. Open University Press, Buckingham, UK, 90-100.

Lawton, M. P. 1983. Time, space and activity. In Rowles, G. D. and Ohta, R. J. (eds), Aging and Milieu: Environmental Perspectives on Growing Old. Academic Press, New York, 41-61.

Means, R. 2007. Safe as houses? Ageing in place and vulnerable older people in the UK. Social Policy and Administration, 41, 1, 65-85.

Moore, S. F. and Myerhoff, B. G. 1977. Introduction: secular ritual: forms and meaning. In Moore, S. F. and Myerhoff, B. (eds), Secular Ritual: Forms and Meanings. Van Gorcum, Assen, The Netherlands, 3-24.

Morris, J. 1993. Independent Lives: Community Care and Disabled People. Palgrave, London.

New Zealand Department of Labour. 2009. Workforce 2020: The Future Demand for Paid Caregivers in a Rapidly Ageing Society. Department of Labour, Wellington.

Nolan, M., Davies, S., Brown, J., Keady, J. and Nolan, J. 2004. Beyond 'person-centred' care: a new vision for gerontological nursing. International Journal of Older People Nursing, 13, 3a, 45-53.

Olaison, A. and Cedersund, E. 2006. Assessment for home care: negotiating solutions for individual needs. Journal of Aging Studies, 2o, 4, 367-80.

Organisation for Economic Co-operation and Development (OECD) 2005. Long-term Care of Older People. OECD, Paris.

Organisation for Economic Co-operation and Development (OECD) 2009. The Longterm Care Workforce: Overview and Strategies to Adapt Supply to a Growing Demand. OECD, Paris.

Parks, J. A. 2003. No Place Like Home. Indiana University Press, Bloomington, Indiana.

Percival, J. 1997. Problems and potentials of sheltered housing; balancing lives in sheltered housing. Ageing Eं Society, 17, 2, 209-14.

Room, G. 1995. Beyond the Threshold: The Measurement and Analysis of Social Exclusion. The Policy Press, Bristol, UK.

Rowles, G. and Chaudhury, H. 2005. Home and Identity in Later Life. Springer Publishing, New York.

Scharf, T., Phillipson, C. and Smith, A. E. 2005. Multiple Exclusion and Quality of Life Amongst Excluded Older People in Disadvantaged Neighbours. Stationery Office, Social Exclusion Unit, Office of the Deputy Prime Minister, London. 


\section{Patrick Barrett, Beatrice Hale and Robin Gauld}

Scharf, T., Phillipson, C., Smith, A. E. and Kingston, P. 2002. Growing Older in Socially Deprived Areas: Social Exclusion in Later Life. Help the Aged, London.

Shield, R. R. 1988. Uneasy Endings: Daily Life in an American Nursing Home. Cornell University Press, Ithaca, New York.

Shield, R. R. 1997. Liminality in an American nursing home: the endless transition. In Sokolovsky, J. (ed.), The Cultural Context of Aging: Worldwide Perspectives. Second edition, Bergin and Harvey, London, 472-91.

Stone, D. 2005. For love nor money: the commodification of care. In Ertman, M. and Williams, J. (eds), Rethinking Commodification: Cases and Readings in Law and Culture. NYU Press, New York, 271-90.

Swenson, M. M. 1998. The meaning of home to five elderly women. Health Care for Women International, 19, 5, 381-93.

Szebehely, M. 1995. The organization of everyday life: on home helpers and elderly people in Sweden. Unpublished PhD thesis, Lund University, Lund, Sweden.

Teather, E. K. (ed.) 1999. Embodied Geographies: Space, Bodies and Rites of Passage. Routledge, London.

Timonen, V. 2005. Policy paradigms and long-term care: convergence of continuing difference. In Taylor-Gooby, P. (ed.), Ideas and Welfare State Reform in Western Europe. Palgrave Macmillan, Basingstoke, UK, 30-53.

Turner, V. 1969. The Ritual Process. Penguin, Harmondsworth, UK.

Twigg, J. 200o. The Body and Community Care. Routledge, London.

Ungerson, C. 2005. Care, work and feeling. Sociological Review, 53, 2, 188-203.

Van Gennep, A. 1909/196o. The Rites of Passage. Vizedom, M. B. and Caffeen, G. L. (Trans.). University of Chicago Press, Chicago.

Victor, C., Scambler, S. J., Marston, L., Bond, J. and Bowling, A. 2002. Older people's experiences of loneliness in the UK: does gender matter? Social Policy and Society, $\mathbf{5}$, $1,27-38$.

Wiles, J. 2005. Home as a new site of care provision and consumption. In Andrews, G. and Phillips, D. (eds), Ageing and Place: Perspectives, Policy, Practice. Routledge, Abingdon, UK, 79-97.

Willner, M. 2000. Towards a stable and experienced caregiving workforce. Generations, 24, Fall, 60-5.

Accepted I4 March 20 I I; first published online 4 May 2 I I I

Address for correspondence:

Patrick Barrett, Political Science and Public Policy Programmes,

The School of Social Science, The University of Waikato,

Private Bag 3105, Hamilton, New Zealand.

E-mail: pbarrett@waikato.ac.nz

\section{CAMBRIDGE}

